TEI

OURNAL OF THE TEXT ENCODING INITIATIVE

\section{Journal of the Text Encoding Initiative}

Issue 11 | July 2019 - June 2020

Selected Papers from the 2016 TEI Conference

\title{
Encoding Crime and Punishment in TEI: The Digital Processing of Early Modern Broadsheets from Vienna
}

Claudia Resch, Daniel Schopper, Tanja Wissik and Daniela Fasching

\section{OpenEdition}

\section{Journals}

Electronic version

URL: http://journals.openedition.org/jtei/1925

DOI: $10.4000 /$ jtei. 1925

ISSN: 2162-5603

Publisher

TEl Consortium

Electronic reference

Claudia Resch, Daniel Schopper, Tanja Wissik and Daniela Fasching, «Encoding Crime and

Punishment in TEl: The Digital Processing of Early Modern Broadsheets from Vienna », Journal of the

Text Encoding Initiative [Online], Issue 11 | July 2019 - June 2020, Online since 25 June 2019,

connection on 01 July 2020. URL : http://journals.openedition.org/jtei/1925 ; DOI : https://doi.org/

10.4000/jtei.1925

For this publication a Creative Commons Attribution 4.0 International license has been granted by the author(s) who retain full copyright. 


\section{Encoding Crime and Punishment in TEI: The Digital Processing of Early Modern Broadsheets from Vienna}

Claudia Resch, Daniel Schopper, Tanja Wissik, and Daniela Fasching

ABSTRACT

In this project note, we introduce a set of printed single broadsheets in German, recently discovered in two of Vienna's libraries, which, thanks to their digitization, annotation, and online publication by the Austrian Centre for Digital Humanities (ACDH) at the Austrian Academy of Sciences (ÖAW), promise to shed new light on the history of crime and punishment in early modern Vienna. The broadsheets, entitled "Death Sentences," belong to a little-explored genre of print media distributed to advertise public executions and have not been subject to closer scholarly examination before now. In their investigation of the sources, the ACDH employs a mixed-method approach combining traditional and digital methods. The sources are transcribed and encoded according to the TEI Guidelines, making use, in particular, of the namesdates module to capture essential information about the convicts sentenced to death. 
The following description gives an overview of the encoding schemes applied and the research possibilities resulting from the use of these methods, and outlines the functionalities of the planned open-access edition. By making the processed and enriched data available to the public, we hope to pave the way for a comprehensive and interdisciplinary analysis of the sources, and to open up an interesting chapter of Viennese history to new audiences.

\section{INDEX}

Keywords: early modern broadsheets, executions in Vienna, annotation, module for names and dates, interdisciplinary approach

\section{Introduction}

1 Due to the steady advance of new technological means of digitizing analogue textual sources in recent years, more and more libraries have started to make use of these new methods, spending increased effort to open up their collections and provide digital access to the vast array of modern sources in their possession. Researchers have benefited considerably from the ever-growing number of page scans that have been captured and are awaiting closer investigation. At the same time, it is well known that historical sources pose a particular challenge to digital processing methods. Their digitization, especially text acquisition and text encoding, often requires additional attention because the performance of automatic tools is still unreliable and prone to errors.

2 In creating the Austrian Baroque Corpus (ABaC:us), ${ }^{1}$ a web-based digital collection of printed German texts with a thematic focus on the topic of memento mori, the Austrian Academy of Science's Austrian Centre for Digital Humanities (ACDH) has met this challenge, producing a thoroughly processed and annotated version of the sources in question. The database, now freely available via an online platform hosted by the ACDH, was built from scratch, which gave the researchers involved in the project ample opportunity to put digitization and processing methods to the test. In the process, they gained much experience concerning the obstacles and limitations specific to the task of applying current means of digital analysis to printed German texts from the early modern period. 
Based on lessons learned during earlier phases of the project, the core team agreed to focus future efforts on expanding the range of machine-readable full-text transcriptions and decided to work on another type of scarce early modern texts. The new project ${ }^{2}$ maintains $\mathrm{ABaC}$ :us's thematic focus on memento mori literature and sets out to digitize and process another suite of sources related to the topic of death, namely a collection of 180 printed single broadsheets referred to as "Death Sentences." Not only may their investigation contribute to uncovering contemporary attitudes to death and the afterlife; it may also bring to light information about public executions and reveal glimpses into the lurid and creatively violent world of crime and criminal justice in eighteenthcentury Vienna.

4 Up until now, the legal history of early modern Vienna has been faced with a paucity of contemporary sources, especially in comparison to cities like London, Paris, or Nuremberg. In contrast to other European cities that started some years ago to investigate local histories of criminal justice and procedure during the eighteenth century, Vienna lacks detailed information about this neglected chapter of its history. The discovery of the collection of broadsheets mentioned above promises to shed new light on the topic. By digitally editing this new set of socalled "Death Sentences" which report on incidences of capital punishment in Vienna between 1700 and 1797, the project group hopes to find evidence for frequently reproduced but unverified conjectures about this fascinating topic. Beyond serving as sources of data, broadsheets of this kind form an independent, if little explored, text genre whose functions and conventions deserve investigation in their own right. The only comparable sources we know of at the moment are similar broadsheets from Salisbury and Munich, which nevertheless differ from the Viennese broadsheets in their length and details like titles and illustrations (Ammerer and Adomeit 2010; Ammerer 2016). While thematically similar, the Vienna "Death Sentences" differ substantially from the earlier, richly illustrated broadsheets from Nuremberg, Augsburg, or Prague, described by Härter (2010) as "Criminalbildergeschichten"-"picture stories" or pictorial narratives about criminals. 


\section{Description of Sources}

5 The "Death Sentences" are housed partly in the Vienna City Library and partly in the Austrian National Library, where another collection of documents (encased in one book) has recently been discovered. Another handful of broadsheets are part of the "History and City Life" collection at the Wien Museum. So far, the prints have not been the subject of much systematic scholarly investigation. This can perhaps be explained with reference to the question of scholarly jurisdiction. While the source material in the collection would definitely present a rich field of study for literary studies, history, and media studies alike, up to now, none of those fields has adopted the topic or paid it any significant attention. This may partly be due to the fact that an in-depth investigation of the material would require an interdisciplinary approach and a pooling of expertise and competences from various fields.

6 Another reason why the area remains underexplored may be a certain confusion regarding terminology: the "Death Sentences" are variously known as “Armesünderblätter" (sinners' leaflets) or "Hinrichtungsflugblätter" (execution leaflets), and have been counted as examples of "Schafott-Literatur" (gallows literature) or simply of "Flugblätter" (flyers). This inconsistency in labeling makes it more difficult to locate and merge the rare references mentioned in secondary sources and impedes scholarly discourse. ${ }^{3}$ In one of the few publications on the matter, Ammerer and Adomeit $(2010,273)$ called for a scholarly edition of the "Death Sentences" which we took as an additional incentive for pursuing our plans for a digital edition that would open up the material to interested scholars from all fields. For this undertaking, our most important objective was the processing and preservation of the texts with the help of an up-to-date inventory of both traditional philological and innovative digital methods.

Figure 1. Selected title pages of some broadsheets.

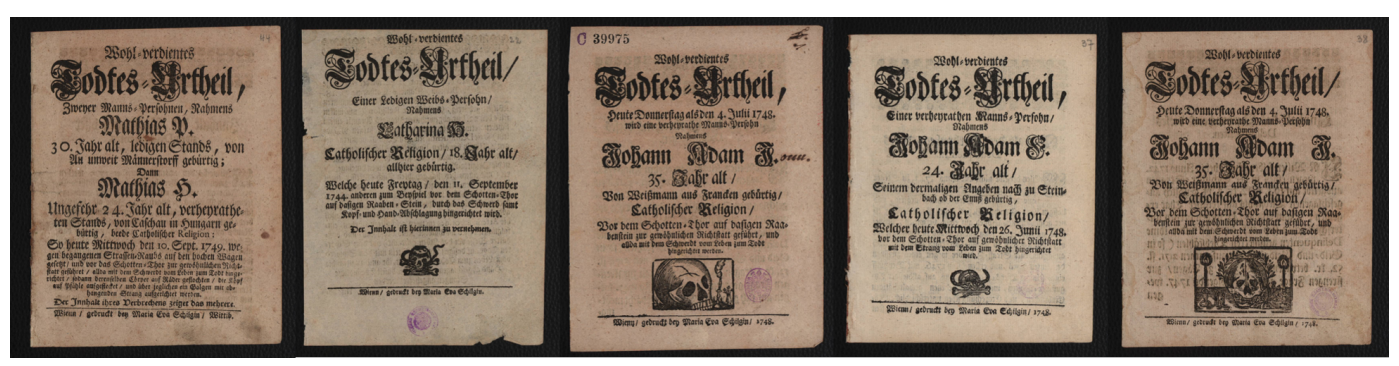

Journal of the Text Encoding Initiative, Issue 11, 25/06/2019

Selected Papers from the 2016 TEI Conference 
7 In order to make the broadsheets publicly available for perusal while also observing the necessary conservation measures and keeping them in good condition, both libraries have produced scans, which are accessible online. ${ }^{4}$ While both libraries have tagged their page scans with keywords, there is, as of yet, no full-text version available; hence, the pages can be browsed and searched according to metadata or broad thematic content, but not queried for specific or verbatim content. The digitally annotated edition developed by the ACDH will remedy this shortcoming.

8 Regarding their physical appearance, the broadsheets have a recognizable format and a somewhat schematic layout. Each print consists of one broadsheet folio folded in the middle, resulting in four pages, of which the first serves as a well-structured title page and provides essential information about the individual cases and executions. As figure 1 shows, some of the title pages are illustrated with little woodcuts showing skulls adorned with common baroque vanitas symbols, such as fading candles, winding snakes, wilting flowers, or hourglasses.

9 All of the broadsheets in our corpus follow a relatively consistent structure starting with the heading “Todesurteil," preceded by the German adjective "wohlverdient." This attribute, which literally means "well-deserved," declares the sentence just or fair and the punishment appropriate to the person's crime. Each broadsheet provides the readers with the convict's personal datacovering, most commonly, their age, place of birth, marital status, religion, and profession. They further give biographical accounts about the life and crime of each "malefactor" followed by descriptions of the sentence and the punishment imposed. In addition to that, the prints can also include genre-specific text forms such as moral speeches, farewell songs, and ballads, furnishing valuable information about the lives and deaths of eighteenth-century criminals in Vienna.

10 The intention behind these anonymous broadsheets is rather unclear: It has been speculated (Czeike 2004,234) that they were sold on the day of executions to provide people with background information on the public spectacle. However, the specific blend of factual information and moral didacticism found in this genre suggests a more complex picture. We can assume that the broadsheets have functions that go beyond the mere distribution of information. They may have served as advertisements or even as souvenirs for the execution events. While they can be seen as early modern precursors of the news media, their darkly fascinating subject matter may also have had a certain sensationalist entertainment value comparable to that of the yellow press news 
that people read with a sense of thrill and titillation. In addition to that, we can assume that the broadsheets also served a political purpose and were printed and distributed with the consent and acquiescence of the authorities in order to reinforce the legitimacy of legal verdicts.

Having reviewed all the various manifestations of this occasion-related and commercially exploited genre, we can see that the "Death Sentences" are a multifaceted format with multiple purposes. Their functions range from providing information about particular criminals and their punishment to advertising the executions as public events, establishing the legitimacy of these disciplinary actions, and finally setting the cases up as moral examples with a deterrent function.

\section{Encoding Crime and Punishment in TEI}

After collecting and compiling the corpus of 180 broadsheets, all primary sources were digitized and carefully transcribed by junior researchers, students, and volunteers and proofread by the core team. As Optical Character Recognition software is well known to be problematic and can perform poorly, especially with historical documents, we decided to manually key in each text in Microsoft Word, following the editing guidelines developed for the Austrian Baroque Corpus. ${ }^{5}$ After manual transcription and double-checking, the final versions of transcripts provide an accurate representation of the original texts and an optimal basis for further markup. Converted to XML, the transcripts were manually annotated following a project-specific customization of TEI P5 (TEI Consortium 2019) which enforces our data model for the descriptions of offenses and provides controlled vocabularies for the values and relevant metadata categories (described in section 4). In the annotation, considerable attention was paid to the structural and semantic features of the texts. Given the limited physical extent of the broadsheets, they show peculiarities that deviate from the TEI Guidelines' document model assumptions in certain details. For example, although all broadsheets have a rather formulaic title section, in about ten percent of the texts it does not completely fill the first page but is directly followed by the main text on the same page. While for this reason the title sections could qualify as simple headings, we found over 60 examples where such a section also contains an imprint, featuring a publishing date or a printer's name. In order to avoid losing the semantics of <docImprint> in such cases and still be able to keep our encoding consistent, we decided to encode all of them as <titlePage $>$ elements, adding a @type attribute with the value "heading" to those which do not cover the full first page of a broadsheet. ${ }^{6}$ Given the 
Guidelines' rather explicit wording ("contains the title page of a text") which seems to discourage this use, we initially considered generalizing the element's name and description in our ODD to $<$ titleBlock>, thus decoupling the structural function from its physical appearance. In the end, however, we decided against this, mainly to ensure interoperability of our project's data. Printers' licenses provide another example of text that poses challenges to the application of the current Guidelines, in the very rare cases when they appear not on the title page but on the back page of a broadsheet, right before the <docImprint>. For those cases, one possible option would have been to add <imprimatur $>$ to the model . pLike. front class. Again, for reasons of interoperability, we have decided to use a workaround, encoding these as <ab type=" imprimatur" $>$. Although this means that we cannot encode the printer's license inside $a<t i t l e P a g e>$ element, this seems like a viable trade-off between semantic accuracy and data reusability.

14 The remaining textual structure of the broadsheets is rather simple but exhibits some characteristic changes over time. While most broadsheets are made up of running text paragraphs, 25 of them (mostly from the 1730s and '40s) also contain verse structured in stanzas which are encoded as $<l g>$ elements. One can observe that from the 1750s onwards, the texts' content structure is expressed in a more explicit manner: recurring sections with formulaic headings like "Inhalt ihres Urtheils." describe the verdicts decided on the offenders. For easier analysis, we have decided to add appropriate @type attributes to such divisions. 
Figure 2. Title page of the "Death Sentence" concerning the case of Peter P(runer), 24 or 25 years old, decapitated in 1750 .

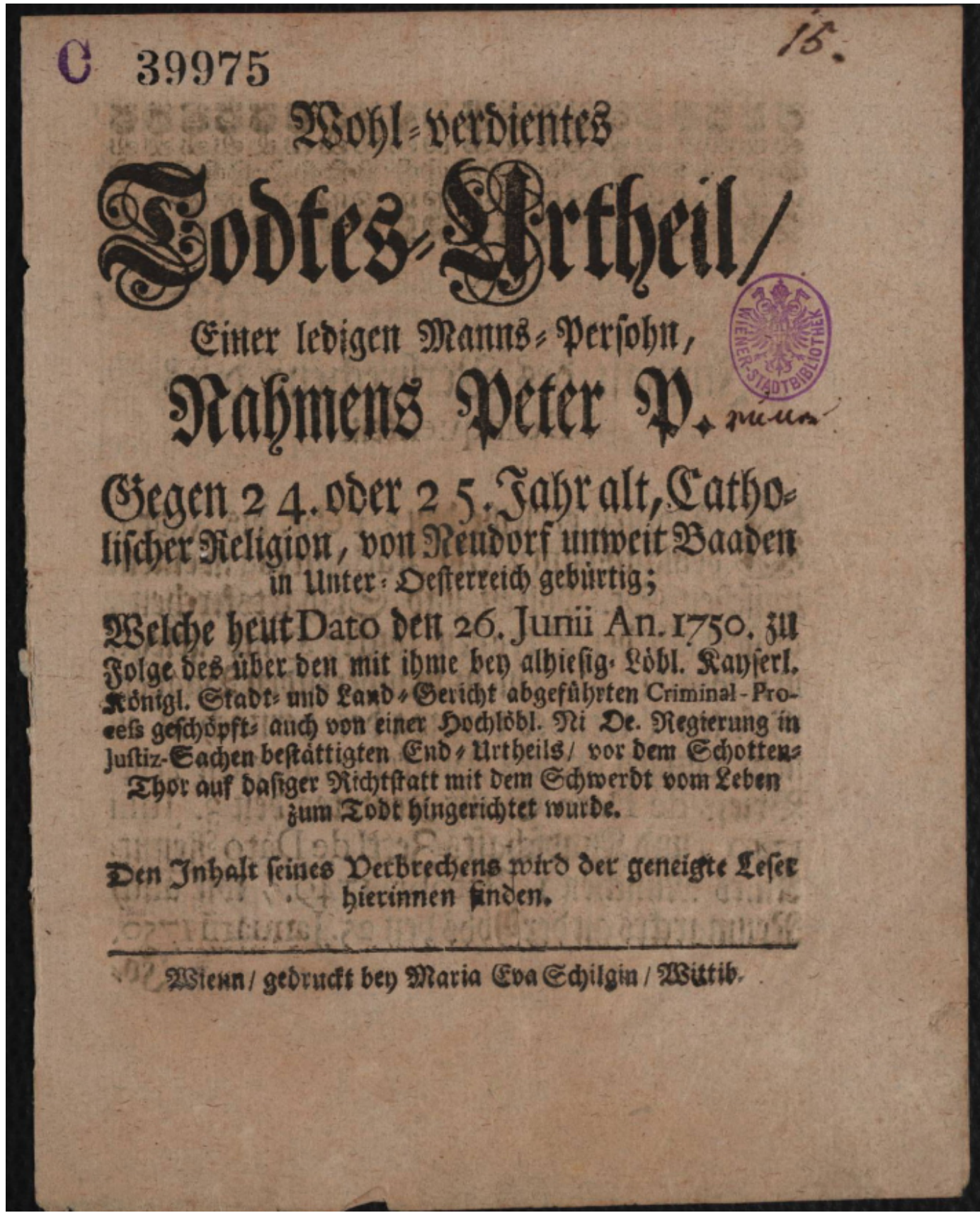

Journal of the Text Encoding Initiative, Issue 11, 25/06/2019 Selected Papers from the 2016 TEI Conference 
15 Additionally, we captured the physical structure of the broadsheets (line and page breaks) as well as some basic renditional features. In the case of the 31 broadsheets that are on hand in more than one version, we encoded the various versions following the parallel segmentation method provided by the textcrit module.

Substantial efforts went into modeling and encoding information on the offenders and their crimes by means of the namesdates module ${ }^{8}$ in order to derive computable data. On the one hand, we encoded personal attributes, such as an offender's name, ${ }^{9}$ sex, ${ }^{10}$ place of birth, age at the time of execution, civil status, religious faith, and occupation. Given that such factual information is always contained in the <titlePage $>$ of each broadsheet, we abstained from tagging the exact locations in the text, but decided to keep only structured data in a <particDesc element in the header. We decided to normalize biographical information wherever this seemed useful within the scope of the project (age, sex, civil state, faith). However, we decided to keep the original wording for aspects which we did not find suitable for quantification. For example, we found too little information regarding the occupations of offenders to allow for relevant comparative analysis across all 180 broadsheets. In such cases, we used the verbatim descriptions from the text, since further classification into a scheme for early modern professions was far beyond the scope of our project.

\section{Example 1. Encoding of personal attributes.}

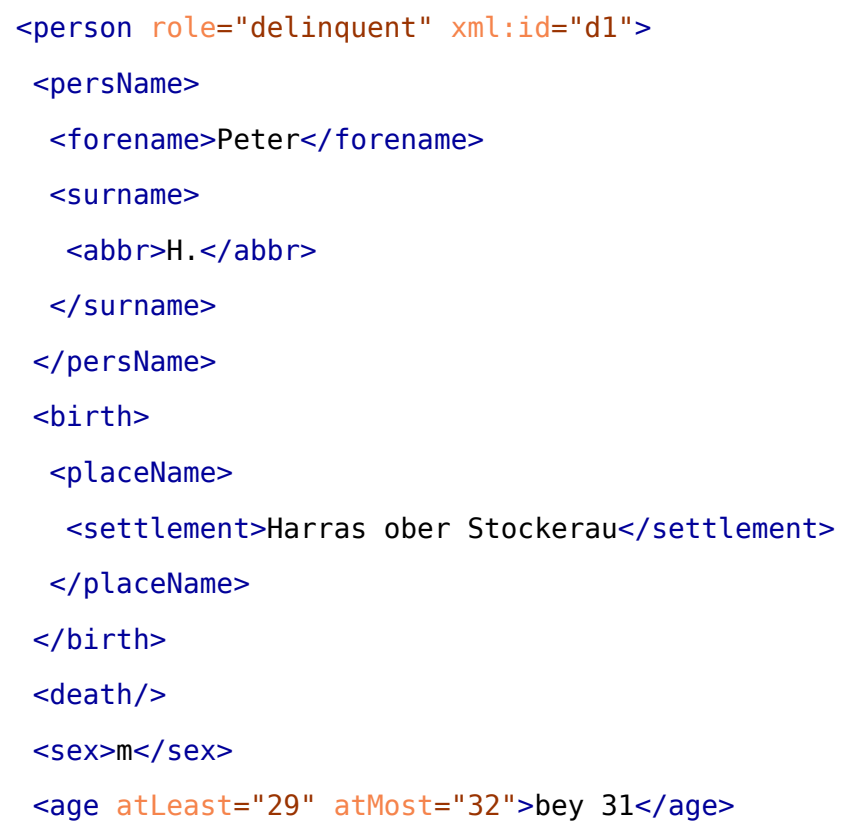




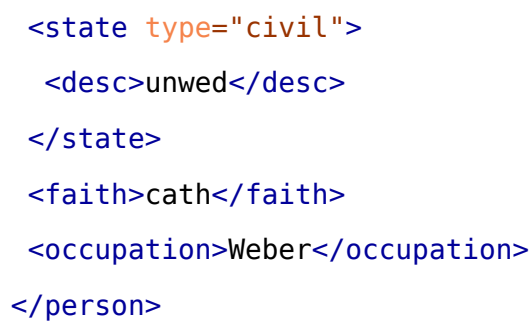

17 Each crime committed by a convict is recorded as an <event > element with additional information drawn from the description in the "Death Sentence." As with the normalization of occupations, we decided not to georeference the place names mentioned in the broadsheets, since there were too many ambiguities.

\section{Example 2. Encoding of different crimes.}

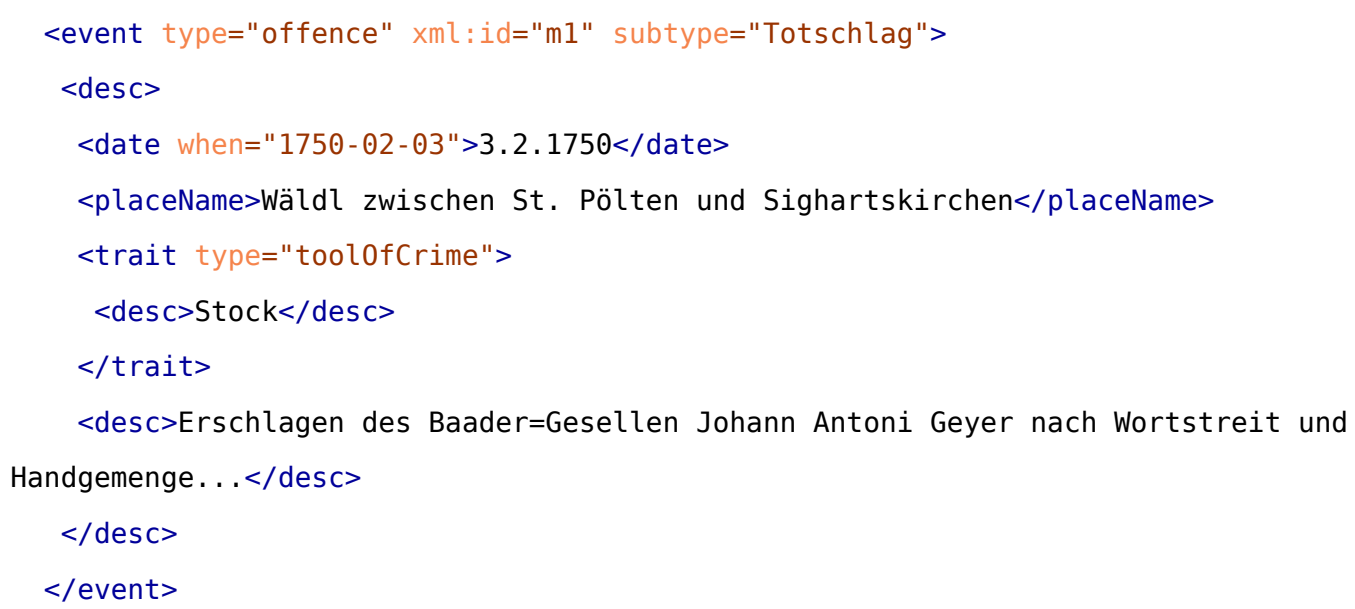

18 Punishments and executions are modeled in the same way. Since the sequence of tortures and the method of execution were related to the crime that a "malefactor" was convicted of, we encoded them as explicitly ordered lists.

\section{Example 3. Encoding of different methods and phases of an execution ${ }^{11}$.}

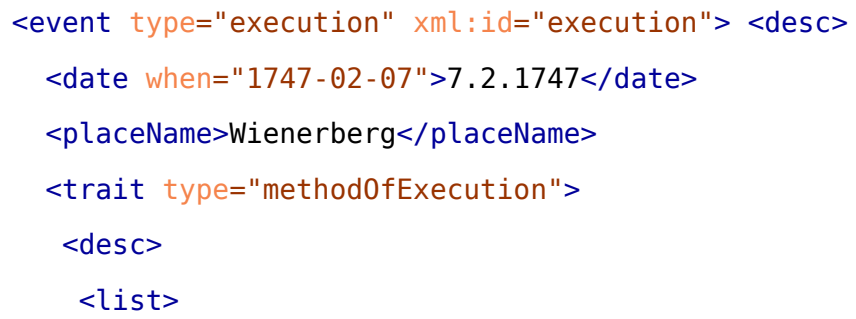




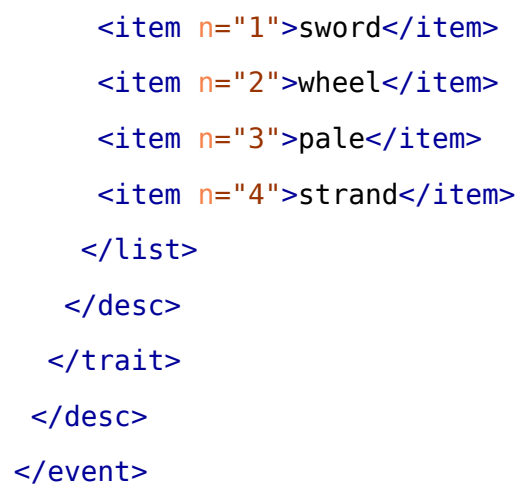

With this granular metadata scheme, researchers are able to pose and answer questions like: What was the average age of "malefactors"? Is there a correlation between the delinquents' social status and their offenses? Can we observe patterns of male and female criminality? What mode of punishment did you face in eighteenth-century Vienna if convicted of child murder? Were infanticides committed exclusively by women?

\section{A Typology of Crimes}

Of the questions that can be investigated through the digitally processed broadsheets, the concepts behind offenses and punishments are among the most interesting ones. In early modern times, offenses and their punishment were generally defined by laws at different levels. During the more than 100 years covered by our collection of historic broadsheets, different laws and penal codes were in force at different times. Among them, there were, for example, the Constitutio Criminalis Carolina: Peinliche Gerichtsordnung Karls V. 1532 (also known as Carolina), the Landgerichtsordnung für Österreich unter der Enns (also known as Ferdinandea), the Constitutio Criminalis Theresiana (also known as Theresiana), and the Allgemeines Gesetzbuch über Verbrechen und derselben Bestrafung (also known as Josephina or Strafgesetzbuch 1787). ${ }^{12}$ Over time, new offenses were defined, legal definitions changed, new punishments were specified, and new terminology was introduced. Terminology could also vary within one legal code. For example, for the "crime" concept, the Theresiana variously uses the words Verbrechen, Delictum, Missethat, and Uebelthat (see example 4). 
The work by the old Bailey Proceedings Online project ${ }^{13}$ on crime typology represents one possible approach to dealing with variations in legal terminology. In order to facilitate statistical analysis, the categories of crime type used in their typology are based on modern legal terminology but are intended to follow the descriptions of offenses used in the original proceedings as closely as possible (Hitchcock et al.2018). Another approach to handling terminology variation is to make use of controlled vocabularies and thesauri based on concrete legal codes. For historical sources and historical legal language, existing legal thesauri, such as EuroVoc, cannot fulfil the requirements of our project. Some of the offenses mentioned in the historical resources-such as "Kirchenraub" (church robbery) or "Urphedbruch" (breach of the oath to keep the peace)-no longer appear in the current legal system. Consequently, we started building domain-specific or even legal code-specific thesauri of historical crime terminology based on the legally binding norms within the period examined in this project and the offenses described in the broadsheets. In these thesauri, the relevant terminology is represented by means of the Simple Knowledge Organization System (SKOS), "a common data model for sharing and linking knowledge organization systems via the Web" (Miles and Bechhofer 2009). In SKOS, concepts are identified through URIs, labeled with natural language strings, documented with various types of notes, and semantically linked to each other. They can also be mapped to concepts in other schemes (Miles and Bechhofer 2009). This is of particular interest for the "Death Sentences" project, as it allows the specific thesauri to be linked to each other as well as mapped to concepts in modern thesauri such as EuroVoc. SKOS data are then expressed as RDF triples. RDF (Resource Description Framework) is another standard for representing information on the web, using subject-predicate-object triples (Cyganiak, Wood, and Lanthaler 2014). Unlike in the Old Bailey Proceedings Online project, the definitions of the concepts are taken from the legal codes in which the concepts originally appeared, as can be seen in example 4.

\section{Example 4. The "Verbrechen" (crime) concept in the thesaurus.}

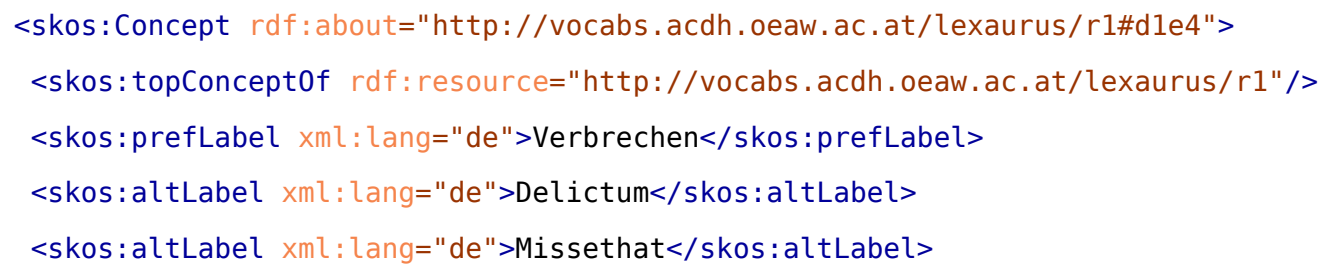




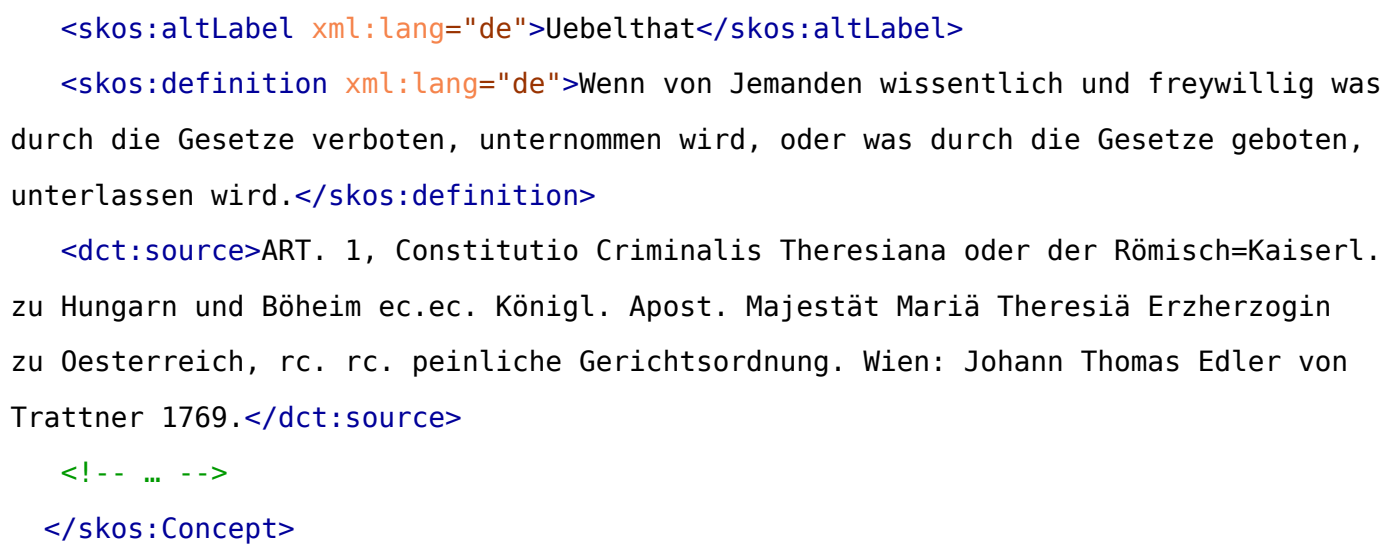

\section{Comparing the sources}

The machine-readable format of the sources also allows us to process and compare them to each other and to put these materials into context with other sources relevant to the topic. At the moment, we are in the process of comparing this data collection with another type of source, namely with the records of a particular religious confraternity whose members accompanied the convicts from life to death and saw a religious duty in burying the abandoned corpses after the execution near St. Charles Church in Vienna. The confraternity kept meticulous records about these works of mercy, which can be used to complement our list of eighteenth-century "malefactors." Additional data can be found in contemporary newspapers such as the Wiennerisches Diarium, which reported on public executions on several occasions.

This additional material has not yet been incorporated into the project. It does, however, help to give further credence to the data recorded in the "Death Sentences" and has provided interesting additional and complementary background information during our research. One example is the case of the "malefactor's" last name, abbreviated to initials in the broadsheets, but included in full in the confraternity records. This information has not been added to the TEI encoding of the "Death Sentences," which, at this point, reflects only the data included in the primary set of sources. It could, however, be the goal of a potential follow-up project to encode these as texts in their own right and merge the information from the various sources into one centralized personography. This could, of course, require the more complex modeling of contradictory information, potentially leading in the direction of current factoid-oriented approaches towards digital prosopography (Bradley and Short 2005). 
The comparison of the execution broadsheets, the confraternity records, and the newspapers also reveals how accounts of the same execution could differ considerably from each other, how the information circulated between the three different formats, and how it was adapted to different purposes. As the example below shows, newspaper articles (just like the "Death Sentences" broadsheets themselves) usually give a more elaborate account than the confraternity records. Concerning the execution of the thirty-year-old Barbara Huberin, the newspaper article on her sentencing provides very detailed information about the woman's offenses and notes that the executioner from Preßburg was unlucky since her beheading required two blows. In contrast, the very brief entry found in the confraternity records gives only the date of the execution and three prosaic lines.

Figure 3. Comparison between a newspaper article in Wiennerisches Diarium and the entry in the confraternity's records.

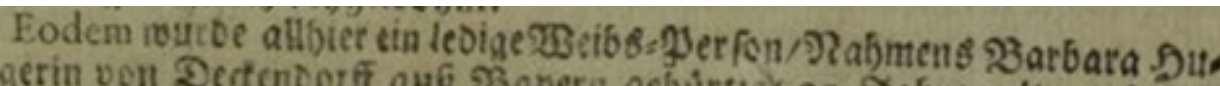
bingerin von Dedenoorff aug. : Ien felbige fibon orcomabl aibier mit oem Sdilling abgefertiget woroen/ und nachgebenos vititáltigs und nabnbaffre Diebfábl begangen / aud oie

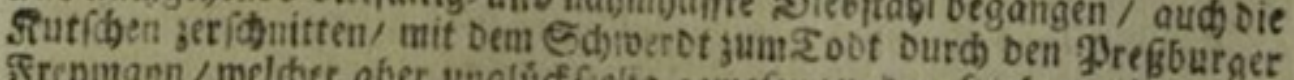
Frepimann / roelder aber unglúcf felig gervefen/ uno 2. .5ieb gegeben/ bith: geribtet.

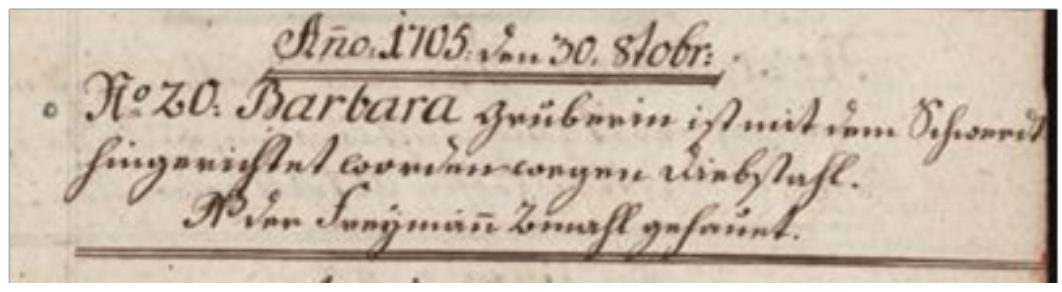

27 The comparison below between the text of a "Death Sentence" and a newspaper article shows only some slight changes to the original wording: in order to shorten the text, the article replaced spelled-out numbers with (Arabic) numerals. Tracking the differences between the two example texts reveals mostly spelling variations. Apart from the adaptation of the introductory formula to fit the new context, no significant changes can be observed. The only substantial lexical change 
was made to the Latin word condemniret, which was translated into the German word verurtheilet (sentenced). The comparison suggests that during certain decades the newspaper publishers tended to simply copy the existing text of the "Death Sentences."

Figure 4. Comparison between a "Death Sentence" and the related entry in the Wiennerisches Diarium, carried out via Juxta, ${ }^{14}$ an open-source tool for collating different text versions.

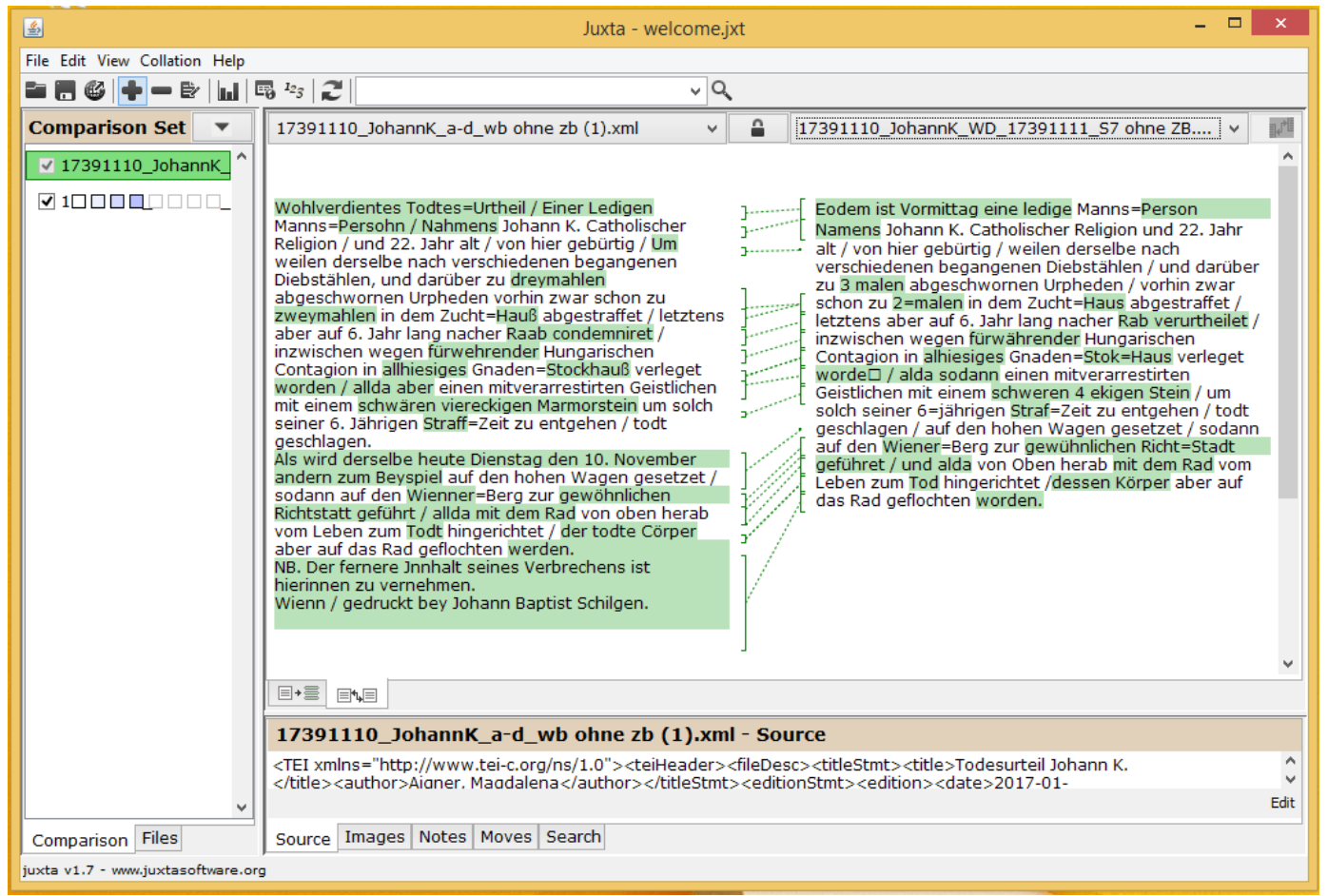

Comparing the sources ("Death Sentences," articles in the newspaper, and confraternity records), it becomes obvious that none of them provides a complete list of all public executions. This is not surprising. First, it is rather unlikely that all "Death Sentences" were preserved and included in the collections available to us. Second, gaps in the newspaper coverage can easily be explained through editorial decisions to report only on some of the more spectacular executions. Third, the confraternity may not have gotten permission to take care of the funeral for each executed person, resulting in the absence of some of the cases from their records. For this reason, we will probably never be able to tell for sure how many executions were actually carried out in eighteenth-century Vienna. The analysis and the comparison have to focus on the representation of the situation as reflected in those records and media that are available to us. 
Thanks to the digital availability of the "Death Sentences," it will also be possible to compare data from Vienna with data from other European capital cities from the same period, a prospect that seems particularly promising in view of the range of international projects dealing with crime and punishment, such as the above-mentioned old Bailey Proceedings Online project in the UK or a group of scholars in the Netherlands who are exploring the relations between crime and gender. ${ }^{15}$ With this in mind, the use of international encoding standards like the TEI is essential in order for this collection to become a comparable dataset for bigger projects.

\section{Opening Up the Sources}

By creating a set of enriched data on the history of penal practices in early modern Vienna, the project team contributes to enhancing knowledge of this little-explored area and lays the groundwork for further research. In order to guarantee that the processed material will be reusable for different purposes, the 180 enriched "Death Sentences" will be made accessible online. The project team will publish the edited basic texts of the rare broadsheets as an open access edition which will include not only the attached facsimiles but also reliable full-text transcriptions, made available in an integrated online environment. Thus, user groups will have options to access, read, and query the broadsheets easily within the web application while also being able to download the XML files for further processing. Besides the common full-text query options, the interface will offer different navigational menus that invite user interaction and allow flexible search strategies (e.g., of keywords and of biographical parameters such as age and sex). Hence, the applied markup not only can be used by the team who carried out the annotation but is also open to other researchers who may wish to take the historical data as a starting point for further inquiry.

Although we consider the project's primary relevance to lie in its service of providing new source material to research communities within disciplines such as literary studies, linguistics, and historical studies (especially crime history and social history), as well as theology and legal studies, we hope that the publication of the digital collection can also be of interest to users outside academia. 
Thanks to the open access format, the web application could be used as an educational tool and may help to open up the fascinating history of early modern everyday life to entirely new audiences. The histories that can be glimpsed and made tangible through the "Death Sentences" with their vivid stories of the life and death of eighteenth-century Viennese "malefactors" are not only accessible to the scientific community but could also capture the interest of a lay audience.

\section{BIBLIOGRAPHY}

\section{References}

Ammerer, Gerhard, and Friedrich Adomeit. 2010. “Armesünderblätter.” In Repräsentationen von Kriminalität und öffentlicher Sicherheit. Bilder, Vorstellungen und Diskurse vom 16. bis zum 20. Jahrhundert, edited by Karl Härter, Gerhard Sälter, and Eva Wiebel, 271-307. Frankfurt am Main: Klostermann.

Ammerer, Gerhard. 2016. “Öffentliche Hinrichtungen inner- und außerhalb der Stadtmauern.” In Stadt und Gewalt, edited by Elisabeth Gruber and Andreas Weigl, 59-86. Innsbruck: Studienverlag.

Bradley, John, and Harold Short. 2005. “Texts into Databases: The Evolving Field of New-style Prosopography.” Literary and Linguistic Computing 20 (Issue Suppl, 1 January): 3-24. doi:10.1093/llc/fqi022.

Cyganiak, Richard, David Wood, and Markus Lanthaler. 2014. "RDF 1.1 Concepts and Abstract Syntax. W3C Recommendation 25 February 2014." W3C. Accessed January 18, 2019. https://www.w3.org/TR/rdf11concepts/.

Czeike, Felix. 2004. Historisches Lexikon Wien in 6 Bänden. Ergänzungsband. Wien: Kremayr \& Scheriau.

Haaf, Susanne, Alexander Geyken, and Frank Wiegand. 2014/15. “The DTA 'Base Format': A TEI Subset for the Compilation of a Large Reference Corpus of Printed Text from Multiple Sources." Journal of the Text Encoding Initiative 8.https://journals.openedition.org/jtei/1114; doi:10.4000/jtei.1114.

Härter, Karl. 2010. “Criminalbilder: Verbrechen, Justiz und Strafe in illustrierten Einblattdrucken der Frühen Neuzeit." In Repräsentation von Kriminalität und öffentlicher Sicherheit. Bilder, Vorstellungen und Diskurse vom 16. bis zum 20. Jahrhundert, edited by Karl Härter, Gerhard Sälter, and Eva Wiebel, 25-88. Frankfurt am Main: Klostermann.

Hitchcock, Tim, Robert Shoemaker, Clive Emsley, Sharon Howard, Jamie McLaughin et al., eds. 2018 The Old Bailey Proceedings Online, 1674-1913. Accessed January 18, 2019. http://www.oldbaileyonline.org/. 
Miles, Alistair, and Sean Bechhofer. 2009. "SKOS Simple Knowledge Organization System Reference. W3C Recommendation 18 August 2009." W3C. Accessed January 18, 2019. https://www.w3.org/TR/skosreference/.

TEI Consortium. 2019. TEI P5: Guidelines for Electronic Text Encoding and Interchange. Version 3.5.0. Last updated January 29. N.p.: TEI Consortium.

\section{Primary Sources}

Allgemeines Gesetzbuch über Verbrechen und derselben Bestrafung (Strafgesetzbuch 1787) (="Josephina"): Patent vom 13. Jänner 1787 JGS. 611/1787.

Constitutio Criminalis Carolina: Peinliche Gerichtsordnung Karls V. 1532 (="Carolina"): Hals oder Peinliche Gerichtsordnung Kaiser Carls V. und des H. Röm. Reichs nach der Originalausgabe vom J. 1533. auf das genaueste abgedruckt und mit der zweiten und dritten Ausgabe v. J. 1533. und 1534. verglichen nebst dem Horixischen Programma: wahre Veranlassung der P. H. G. O.: und einer Vorrede worin der Werth und Nutzen dieser Ausgabe gezeigt, und zu der gelehrten Geschichte des teutschen peinlichen Rechts zuverlässige Nachrichten mitgetheilt werden. 1781. Gießen: Johann Christian Krieger. Accessed April 27, 2017. http://data.onb.ac.at/ABO/ \%2BZ155226907.

Constitutio Criminalis Theresiana oder der Römisch=Kaiserl. zu Hungarn und Böheim ec.ec. Königl. Apost. Majestät Mariä Theresï̈ Erzherzogin zu Oesterreich, rc. rc. peinliche Gerichtsordnung. (="Theresiana”). 1769. Wien: Johann Thomas Edler von Trattner. Accessed April 27, 2017. http://reader.digitale-sammlungen.de/de/fs1/ object/display/bsb10322049_00007.html.

Landgerichtsordnung für Österreich unter der Enns(="Ferdinandea"): Reformation vnnd ernewerung der Lanndtgerichts ordnung so weilendt Kaiser Maximilian hochlöblicher gedechtnuß im Ertzhertzogthumb Osterreych vnnder der Enns aufgericht hat. 1555. Wien: Singriener. Accessed April 27, 2017. http://data.onb.ac.at/ABO/ \%2BZ175973506.

\section{NOTES}

1 The Austrian Baroque Corpus, available at https://acdh.oeaw.ac.at/abacus/ (accessed January 18, 2019) since 2015, is a result of the project Text-Technological Methods for the Analysis of Austrian Baroque Literature (Principal Investigator: Claudia Resch, March 2012-September 2014), supported by the Österreichische Nationalbank's Anniversary Fund.

2 The project described here is part of a wider research project, Mortuary Cult in Vienna, which was funded by the city of Vienna (Project number: LWI0240; duration: 2014-18). 
3 In our discussion, we have decided to use the term "Death Sentences" ("Todes-Urteile") since that is the title found in the sources themselves.

4 See the digital collection of broadsheets in the Vienna City Library available at http:// www.digital.wienbibliothek.at/wbr/nav/classification/466442?s=date (accessed January 18, 2019) as well as the collection at the Austrian National Library, Signatur 303.950-B Alt Mag, where each "Death Sentence" is available in one single document, such as, for example, the text about Mathias P. and Anton H. (accessed January 18, 2019) http://data.onb.ac.at/ABO/\%2BZ175973506.

5 See Austrian Baroque Corpus (ABaC:us) website, accessed January 18, 2019, https:// acdh.oeaw.ac.at/abacus/index.html?path-detail=content/Annotation.xml.

6 This tagging is consistent with the "DTA base format" which proposes this very value for title sections of newspapers and other similar material. The DTABf authors point out the limitations of <titlePage> (Haaf, Geyken, and Wiegand 2014/15, para. 37).

7 TEI Consortium 2019 (P5: Guidelines for Electronic Text Encoding and Interchange, Version 3.5.0., January 29, 2019, https://www.tei-c.org/Vault/P5/3.5.0/doc/tei-p5-doc/en/html/refrdgGrp.html).

8 TEI Consortium 2019 (P5: Guidelines for Electronic Text Encoding and Interchange, Version 3.5.0., January 29, 2019, section Names, Dates, People, and Places, https://www.tei-c.org/Vault/P5/3.5.0/ doc/tei-p5-doc/en/html/ND.html).

9 In the vast majority of cases the "Death Sentences" do not give offenders' full names, but provide only the initial of the surname, presumably to protect the offenders' identities and their families' reputations. In order to provide the offenders' full names, their last names would have to be reconstructed in reference to additional sources. For the possibility of linking our dataset to other sources, see section 5 .

10 The sources of course predate a conceptual differentiation between sex and gender as we would draw it now, and the textual representation categorizes offenders within binary sex/gender categories by referring to them as "Weibsperso[h]n" (woman person) or "Mannsperso[h]n" (man person), respectively. While these terms themselves are not marked with regards to whether they refer to (what we think of as) sex or gender, a differentiation that in the German language still 
does not exist on the level of single words, we have decided to refer to the category as "sex," as we take that biological presentation is what counted and was documented in a legal setting, and we arguably do not have any information about the person's gender identity as separate from that. 11 The value "pale" is a representation of the German term "Pfahl" (as used in the historical documents) and refers to execution by impaling. The value "strand" is a representation of the German term "Strang" (as used in the historical documents) and refers to execution by hanging.

12 For detailed citations, see the list of primary sources in the reference list.

13 See https://www.oldbaileyonline.org/, accessed January 18, 2019.

14 See Juxta, "About," accessed January 18, 2019, http://www.juxtasoftware.org/about/.

15 See the website "Crime and gender 1600-1900: a comparative perspective," accessed January 18, 2019, http://www.crimeandgender.nl/.

\section{AUTHORS}

\section{CLAUDIA RESCH}

Claudia Resch is a senior researcher and project leader at the Austrian Centre for Digital Humanities (ACDH) of the Austrian Academy of Sciences. Her current research focuses on German literature of the early modern period and the application of literary and linguistic computing in a corpus-based approach to textual issues. Key areas covered are historical linguistics, text stylistics, and annotation problems associated with nonstandard varieties of early modern German. Since 2012 Claudia Resch has been a lecturer in the Department for German Philology of the Ludwig-Maximilians-Universität in Munich, where she teaches digital approaches to textual sources.

\section{DANIEL SCHOPPER}

Daniel Schopper coordinates the ACDH's working group on Data, Resources, and Standards. His fields of interest include data modeling and conversion techniques, text representation and encoding, methodological challenges in a digital environment, and text-related software development. At the ACDH he is responsible for the creation and curation of standards-based digital resources like dictionaries or digital editions, covering the full cycle of scholarly data production. He is enthusiastic about innovative systems that help scholars reflect on, exploit, and extend the possibilities of the digital paradigm in the arts and humanities. 


\section{TANJA WISSIK}

Tanja Wissik is a senior researcher at the ACDH of the Austrian Academy of Sciences and teaches at the Department of Translation Studies of the University of Graz. She works on numerous national and international research projects in the field of language resources and digital humanities. Her research interests include digital language resources and technologies, especially terminological resources and corpora, workflow research, variational linguistics, and the teaching of $\mathrm{DH}$ technologies and methods.

\section{DANIELA FASCHING}

Daniela Fasching joined the ACDH as a research intern in 2016 and is now part of the Network \& Outreach team. After participating in the ACDH's TEI Conference, she has contributed to the Death Sentences project, drawing on her background in German studies, art history, and English and American studies. 